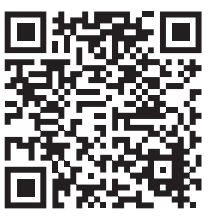

* Subcomisionada Médico de la CESAMED, Puebla. México.

Correspondencia: MRG, pipinilla3@hotmail.com Conflicto de intereses: No hubo conflicto de intereses.

Citar como: Ramírez GM La comisión de arbitraje médico en la pandemia ocasionada por COVID-19 Rev CONAMED. 2021; 26(supl. 1): s34-s37. https:// dx.doi.org/10.35366/102579 Financiamiento: $\mathrm{Se}$ utilizaron recursos propios.

Recibido: 29/10/2021. Aceptado: 29/10/2021.

\section{La comisión de arbitraje médico en la pandemia ocasionada por COVID-19}

The medical arbitration commission in the pandemic caused by COVID-19

Mayda Ramírez García*

\section{INTRODUCCIÓN}

El artículo $4^{\circ}$ de la Constitución Política de los Estados Unidos Mexicanos establece que toda persona tiene derecho a la salud, lo que incluye el derecho de acceso a un sistema de protección que ofrezca a todas las personas las mismas oportunidades de disfrutar del grado máximo de salud que se pueda alcanzar. Asimismo exige un conjunto de criterios sociales, entre ellos la disponibilidad de servicios de salud, condiciones de trabajo seguras, vivienda adecuada y alimentos nutritivos.

El sistema mexicano de salud cuenta con una amplia oferta de servicios, en general se destinan a tres distintos grupos de beneficiarios:

1. Los trabajadores asalariados, los jubilados y sus familias.

2. Los autoempleados, trabajadores del sector informal, desempleados y personas que se encuentran fuera del mercado de trabajo, y sus familias.

3. La población con capacidad de pago.

Un rasgo que caracteriza a los servicios de salud en nuestro país es que se brindan de manera fragmentada. De forma independiente al tipo de afiliación con el que cuenten los ciudadanos, pueden presentarse inconformidades entre las partes involucradas como resultado de la prestación de servicios médicos, así como de sus consecuencias.

Los conflictos que se originan con las controversias en materia de salud no escapan a la necesidad de una justicia pronta y expedita, sobre todo las exigencias relacionadas con el servicio médico que recibe una sociedad más y mejor informada, y con mayores expectativas. En nuestro estado, la labor de la Comisión Estatal de Arbitraje Médico de Puebla (CESAMED) es parte importante de ésta dinámica.

\section{ANTECEDENTES}

La creación de la CESAMED se formalizó por decreto del Ejecutivo del estado en 1999, desde entonces se instituyó como un órgano público desconcentrado de la Secretaría de Salud del Estado, que goza de autonomía para asesorar y orientar tanto a usuarios como a prestadores de servicios médicos; así como para recibir quejas, investigar irregularidades en la prestación de estos servicios, emitir opiniones y laudos; con el propósito de contribuir a tutelar el derecho a la protección de la salud, 
así como a mejorar la calidad en la prestación de los servicios médicos en un entorno de respeto a sus derechos y obligaciones; y con apego a la normativa aplicable, la lex artis médica. Que es el criterio valorativo para calibrar la diligencia exigible en todo acto o tratamiento médico, así como a la deontología relacionada con la ética, los deberes y principios que afectan a una profesión, en este caso la médica.

Tanto las organizaciones públicas como privadas de todo el planeta, se han visto afectadas por la contingencia sanitaria ocasionada por el virus del SARS-CoV-2 (COVID-19), la cual es reconocida por la Organización Mundial de la Salud, así como por el gobierno Federal y del Estado, como una enfermedad grave de atención prioritaria.?

Las políticas implementadas para disminuir los efectos de esta emergencia sanitaria han tenido un fuerte impacto en la actividad económica y, en particular, en las modalidades del trabajo y empleo; gran parte de la población económicamente activa ha sufrido afectaciones para continuar con sus actividades después de los diferentes cierres dispuestos por las autoridades.

Las actividades consideradas no esenciales adoptaron en muchos casos una modalidad virtual, lo que ha permitido, en la medida de lo posible, la continuación de las tareas desde los hogares, destacando que, conforme a los diversos acuerdos de las autoridades sanitarias, la función arbitral no es considerada esencial. Aunque no podemos dejar atrás nuestra labor de gestión inmediata y asesorías, que resultan de mayor utilidad en presencia del SARS-CoV-2 (COVID-19) que multiplicó la búsqueda de los servicios de salud en todos los niveles. ${ }^{2}$

Es conveniente señalar que, en el contexto de la pandemia, es aún más importante que la población cuente con mecanismos que, sin perjuicio de la actuación de las instancias jurisdiccionales en la solución de conflictos, contribuyan a tutelar el derecho a la protección de la salud, así como a mejorar la calidad en la prestación de los servicios médicos. Para lograr tal objetivo, es necesario contar con un órgano al cual puedan acudir los usuarios y prestadores de servicios médicos con la finalidad de resolver, en forma amigable y de buena fe, posibles conflictos derivados de la prestación de dichos servicios, lo cual contribuye a aligerar las controversias que tendrían que resolver los órganos jurisdiccionales, sin pretender sustituirlos.

Al respecto y desde el inicio de la pandemia, para quienes encabezamos ésta institución ha sido prioritario cumplir con nuestro mandato, así como asegurar la salud y la integridad física de todos los que laboramos en ella; lo que ha implicado la adaptación de las dinámicas de trabajo y la colaboración a distancia a través de reuniones remotas, aprovechando al máximo los recursos tecnológicos a nuestro alcance.

Entre las gestiones que hemos realizado recientemente, en abril de 2020 se empezaron a limitar actividades que en condiciones normales se hubieran desarrollado en nuestras instalaciones. Asimismo, en cumplimiento a la Guía de Acción para los Centros de Trabajo, se ha implementado un control general para el ingreso, permanencia y salida de nuestras instalaciones, el cual inicia con la toma de temperatura, incluye además uso de cubre bocas y caretas, aplicación de gel, separación de las estaciones de trabajo compartidas con una distancia mínima de 1.2 a 2.0 metros de distancia; también se orientó al personal sobre la identificación de signos de la enfermedad. ${ }^{3}$

Además, se aplicó resguardo domiciliario al personal en condición de vulnerabilidad; se reorganizaron las jornadas laborales para minimizar el contacto mediante guardias estratégicas en el área médica y jurídica, organizadas de tal forma que, en todo momento, sea posible brindar atención personalizada a los usuarios que se presentan en nuestras instalaciones.

A pesar de estas medidas, sufrimos la pérdida irreparable de un miembro del equipo, a quien honramos en nuestra memoria.

En respuesta a la limitación del arribo por parte del público a nuestras instalaciones con el propósito de presentar una inconformidad o recibir orientación, nos dimos a la tarea de ofertar los servicios de la Comisión Estatal de Arbitraje Médico CESAMED al público en general, a través de las distintas redes sociales, entre ellas Twitter, Instagram, Facebooky Whatsapp. Además, se diseñaron cápsulas informativas sobre nuestras funciones y atribuciones, así como nuestra ubicación y los medios de contacto para recabar inconformidades.

A través de estos mecanismos, continuamos orientando a la población y hacemos hincapié en lo relacionado con la COVID-19. 
Entre los principales resultados alcanzados del 1 de enero al 31 de diciembre de 2020, y envueltos en las restricciones que han representado los cambios del semáforo epidemiológico, se prestaron 353 servicios, los cuales se componen de la siguiente manera: 145 asesorías, 95 orientaciones, 54 gestiones inmediatas, 20 quejas, 39 dictámenes (Figura 1).

Como parte de la estrategia de difusión en los diferentes medios televisivos y redes sociales, en el mes de enero se llevó a cabo una entrevista en el programa «México tenemos que hablar» del canal VCN, en la cual se habló sobre nuestras funciones y cómo acceder a ellas.

Con el mismo propósito, en febrero de 2021 se dio una entrevista en el programa «Los otros datos». Asimismo, en junio se recibió a Televisa Puebla en nuestras instalaciones, para que, a través de sus plataformas y contenidos, se ofrezca información sobre nuestros servicios.

En febrero de 2021 se realizó el webinar «Funciones y atribuciones de la CESAMED» impartido por el Dr. Rogelio Hernández, asesor médico en la subcomisión médica de esta comisión.

En marzo se realizó un webinar más, éste sobre responsabilidad médica, impartido por la Mtra. Ana Verónica Cruz Leyva.

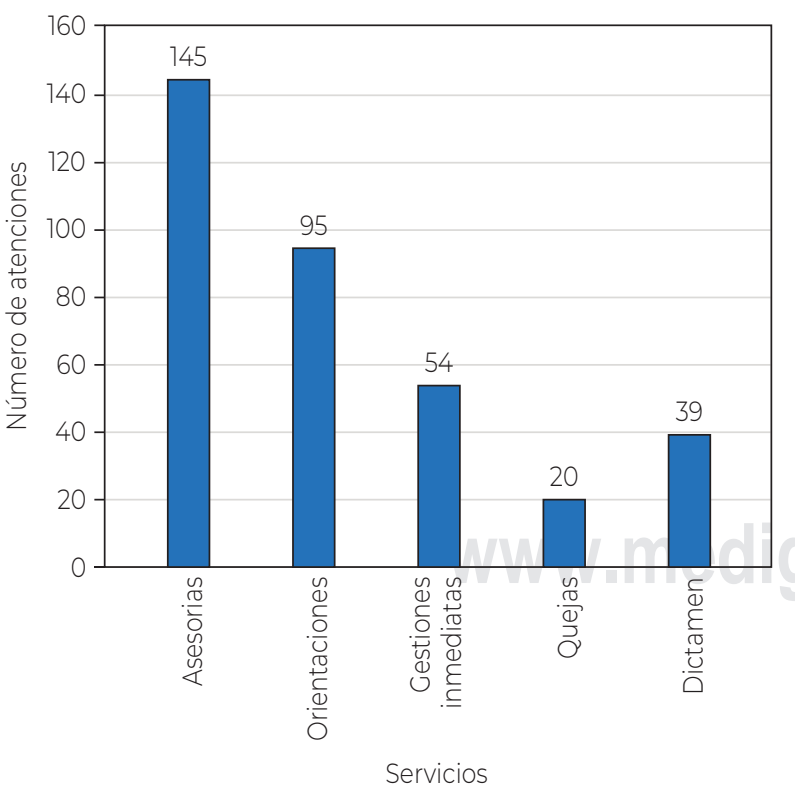

Figura 1: Total de atenciones brindadas en la CESAMED Puebla en el año 2020.

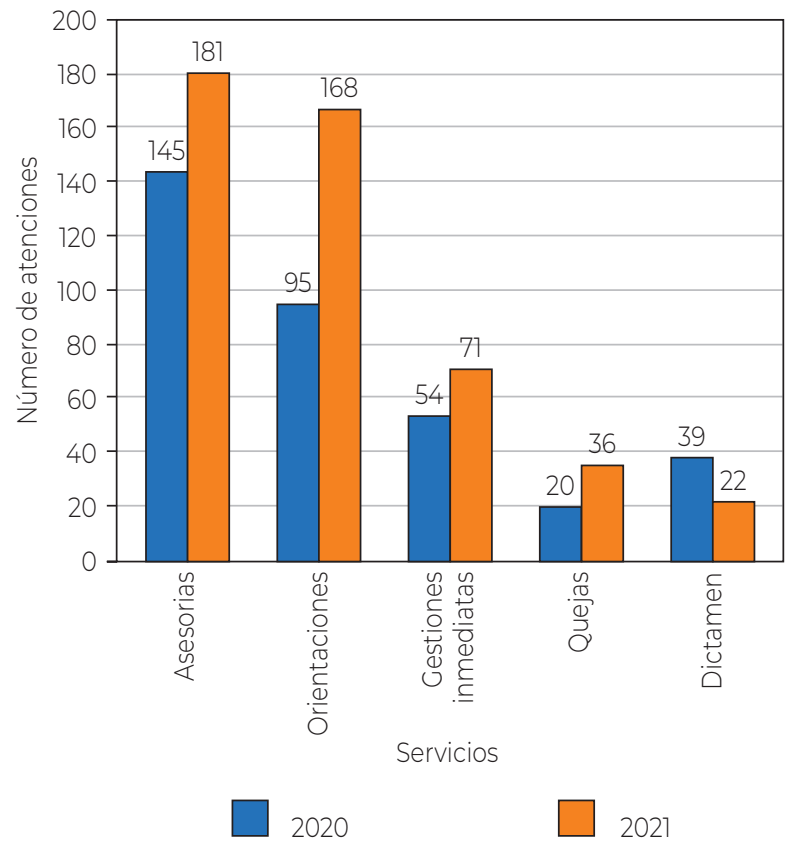

Figura 2: Comparativo de las atenciones brindadas en la CESAMED Puebla en el año 2020 y 2021.

En julio de 2021 se realizó un tercer webinar, denominado «Odontología y derecho, punto de encuentro», impartido por la Dra. Mónica Suárez Ledezma.

En agosto se celebró el webinar más reciente, sobre las funciones y atribuciones de la CESAMED, impartido por la Mtra. Ana Verónica Cruz Leyva.

Asimismo, el 18 de junio 2021 se realizó una jornada de atención médico-paciente a través de un módulo instalado en el municipio de Zacapoaxtla, donde se recibieron quejas y se brindó asesoría y orientaciones por parte nuestros asesores médicos y jurídicos.

De la misma manera, el 22 de julio se instaló un módulo para la atención y servicios de asesorías en el municipio de Oriental; dichos módulos cuentan con la participación de asesores médicos y jurídicos.

El 21 de septiembre se acudió al municipio de Santa Isabel Cholula, donde se colocó un módulo de información y atención sobre nuestras funciones y servicios a la población.

Por último, en el periodo del 1 de enero al 31 de septiembre 2021 se han otorgado 478 servicios, mostrando un aumento a comparación de los servicios solicitados en 2020 (Figura 2). 


\section{CONCLUSIÓN}

La salud es un derecho humano innegable y un elemento indispensable para el bienestar de las personas y la sociedad en todos los ámbitos y niveles de vida.

Su conservación representa un desafío para los profesionales en la materia, quienes día a día se enfrentan al riesgo de contagio en un escenario con falta de recursos humanos suficientes para la situación generada por la alerta sanitaria originada por el SARS-CoV-2, lo que incluso llega a provocar estrés laboral.

Aunado a lo anterior, el sector médico enfrenta adversidades adyacentes, en medio de la politización de la información, así como de la desinformación sobre la salud. Para realizar su labor, los distintos niveles de atención médica han tenido que adecuar los sistemas médicos de triaje, relacionados con la gestión del riesgo por el manejo seguro de los flujos de pacientes cuando la demanda y las necesidades clínicas superan a los recursos.

Asimismo, la conversión de hospitales de atención para pacientes COVID ha puesto en un plano aparte la atención de padecimientos de otra naturaleza; algunos servidores médicos han cambiado sus estrategias de trabajo, limitando la atención a pacientes no COVID o implementando su atención a manera de videoconsulta.

Estas variantes en la atención médica no descartan la mala comunicación de los usuarios con los prestadores de servicios de salud; situación que hemos visto reflejada en los diferentes medios de comunicación, en los cuales se hacen manifiestas quejas de pacientes o de sus familiares: negación de la atención, falta de información sobre el estado de sus pacientes, o enfermos que a su parecer fueron mal diagnosticados.

Ante éste panorama es relevante nuestra labor como medio de atención para solucionar controversias médicas e incentivar la mejora en la calidad de la atención de los servicios de salud.

Las circunstancias en las cuales la mayoría de la población adulta cuenta con un esquema completo de vacunación contra COVID, y el regreso seguro y escalonado de las actividades laborales y económicas en el estado de acuerdo con el semáforo epidemiológico, han permitido la movilización de la población fuera de los hogares, lo que facilita y favorecerá la búsqueda de nuestros servicios.

Estamos obligados a redoblar esfuerzos para lograr un entorno de seguridad, tanto para el público al que atendemos como a nuestro personal; a continuar con el uso de herramientas tecnológicas que nos permitan comunicarnos con la población; y a constituirnos como un medio eficaz para la resolución de conflictos en la atención médica.

\section{REFERENCIAS}

1. Secretaría de Gobernación (SECOB). Acuerdo por el que se declara emergencia sanitaria por causa de fuerza mayor, a la epidemia de enfermedad generada por el virus SARSCoV-2 (COVID-19). Ciudad de México, México: Diario Oficial de la Federación; 2020. Disponible en: https://www.dof.gob. mx/nota_detalle.php?codigo=5590745\&fecha=30/03/2020

2. Ayuntamiento de Puebla. Punto de acuerdo mediante el cual se establecen las directrices para la reapertura de actividades económicas, sociales y educativas en el municipio de puebla; 2020. Disponible en: https://gaceta. pueblacapital.gob.mx/publicaciones/puntos-de-acuerdo/ item/352-res-2020-097-punto-de-acuerdo-mediante-elcual-se-establecen-las-directrices-para-la-reaperturade-actividades-economicas-sociales-y-educativas-en-elmunicipio-de-puebla

3. Secretaria del Trabajo y Previsión Social. Guía de Actuación para los Centros de Trabajo ante el COVID-19. 2020. Pp-7-36. Disponible en: https://www.gob.mx/ cms/uploads/attachment/file/548062/GUI_A_DE_ ACCIO_N_PARA_LOS_CENTROS_DE_TRABAJO_ANTE_ EL_COVID-19_24_04_20_VF.pdf 